\title{
Uveal colobomata and other anomalies in three generations of one family
}

\author{
L. M. T. GOLLUM \\ Department of Ophthalmology, Cardiff Royal Infirmary
}

It is well recognized that typical colobomata of the uveal tract may show a strong hereditary tendency and that the transmission is usually dominant (Kelecom, 1967). Associated with such colobomata there may be other ocular anomalies, such as microcornea (Srivastava, I96ı ; Batra and Paul, I967), microphthalmos (Petrovic-Ducic, I959; Duggan and : Hassard, I96I; Zeiter, I963), aniridia (Lewallen, I958; Menderes, I962), medullated iे nerve fibres (Roy, ig65), nystagmus (Lewallen, I958; Monahan, Hill, and Venters, I967), heterochromia of the iris (Ammann, Klein, and Jöhr, r964), persistence of primary vitreous (François, Neetens, and Carpentier, I964), heterotopia of the macula (Bernhard, I898), or cataract (Yanoff, Frayer, and Scheie, I963). Only rarely, however, have systemic abnormalities been reported (Duggan and Hassard, r96r ; Ammann and others, ı 964; Zolog, I966; Zaikova and Bulatovskaya, I968). In this communication a family is presented with a high incidence of uveal colobomata in three generations, and in addition other anomalies, both ocular and systemic (Figure).

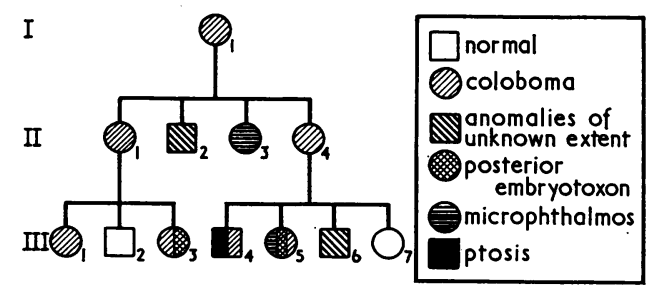

FIGURE Family tree

\section{Case presentations}

An infant aged 2 weeks (Patient III, 3) was referred to the Eye Clinic because of the abnormal appearance of her pupils. On questioning her mother, it was noted that this was the third generation of the family to have eye abnormalities. The pedigree was traced as far as possible and all available members of the family were examined.

Patient I, I, a 42-year-old woman, had bilateral typical iris colobomata which extended to involve the choroid on both sides. The maculae and discs were normal and the visual acuity was $6 / 6$ in each eye. There were localized cortical lenticular opacities bilaterally in the quadrants beneath the colobomatous areas. The appearance of the lens changes suggested that they were probably congenital in origin. No other abnormalities were present.

Patient II, I, a 22-year-old woman, had bilateral typical iris colobomata of the bridge variety. The choroid was also involved on both sides, the lesion on the right side extending to engulf the disc and macula. The visual acuity in the right eye was hand movements and in the left 6/9. No other abnormalities were present. 
Patient II, 2, a 24-year-old man, was not available for examination as he was in a mental institution in South Africa. His mother (Patient I, I) stated that he had iris colobomata bilaterally as well as a hare lip and cleft palate, and was severely mentally retarded.

Patient II, 3, a 20-year-old girl, was mildly mentally retarded and had gross microphthalmos on the right side. The left eye was normal with a visual acuity of 6/9. She had worn a cosmetic lens in the right socket since the age of 10 years.

When she was aged 8 months she had an operation for hare lip and one year later had her cleft palate repaired.

Patient II, 4, a 26-year-old woman, had a typical iris coloboma on the left side which extended to involve the choroid, including both the disc and macula. The right eye was normal with a visual acuity of $6 / 4$.

Patient III, 1, an 18-month-old girl, had bilateral typical iris colobomata which also involved the choroid on both sides. The discs and maculae were normal. No other abnormalities were present.

Patient III, 3, a 2-week-old baby girl, (the propositus), had a bridge coloboma of the right iris in the usual position; this coloboma extended to involve the choroid, leaving the disc and macula undisturbed. There was a choroidal coloboma on the left side, and bilateral posterior embryotoxon Corneal diameters were normal as were intraocular pressures. She had a large cavernous haemangioma of the right breast.

Patient III, 4, a 4-year-old boy, had a moderately severe right ptosis which had resulted in the adoption of a head tilt. The right eye was otherwise normal but there was a minimal coloboma of the left choroid in the usual site, not involving the disc or macula. Facial asymmetry and a basal systolic cardiac murmur were also noted.

Patient III, 5, a 21-year-old girl, had bilateral typical iris colobomata which extended to involve the choroid on both sides. She also has mild microphthalmos and bilateral posterior embryotoxon. In addition both pupils were ectopic, being displaced downwards and nasally. Slight horizontal nystagmus was noted. On three occasions her eyes had been examined under general anaesthesia and an intraocular pressure of up to $45 \mathrm{~mm}$. $\mathrm{Hg}$ had been recorded in the right eye. No surgical procedure has been carried out to date, and we have no record of any detailed gonioscopic examination.

No. II, 6, a still-born boy, was an anencephalic with a hare lip and cleft palate. This information was obtained from the hospital records; no observations were made on his ocular state.

\section{Discussion}

Although the transmission of iris colobomata is usually dominant, it is often found that there is irregular penetrance with one generation sometimes being missed (Duke-Elder, 1964; Kelecom, 1967). In the pedigree reported in this communication there is almost 90 per cent. penetrance. Mello e Oliveira (I96I) observed that the genes responsible for such defects were very labile resulting in a marked variation in expression. This is indeed a feature of the present series. It is interesting to note that with each generation there seems to be a tendency for the anomalies to become more gross. McKusick (1966), however, stated that this was not a true increase in the severity of the abnormalities but rather an artefactual phenomenon.

The occurrence of microphthalmos in association with uveal colobomata is not infrequent (Duggan and Hassard, I96r; Zeiter, I963; Ernyei, 1969; Hauschild, 1969). In this family different degrees of microphthalmos are present varying from an almost totally 
empty socket to a slight reduction in the size of the eye. It was possible to produce good cosmetic result in the severely affected patient by the use of a cosmetic contact lens

The presence of posterior embryotoxon may indicate that even more widespreaळ abnormalities of the anterior chamber may coexist, leading to a fall in aqueous outflow The mere presence of posterior embryotoxon does not in itself lead to raised intraocular pressure (Malik, Singh, and Gupta, 1969), and it has been shown (Burian, Braley, and Allen, 1954) that i 5 per cent. of normal persons exhibit this anomaly. Coscas (1969) discussed the relationship of embryotoxon to glaucoma. Even where there is no evidenc零 of embryotoxon, abnormal tissue may occur in the filtration angle (Jerndal, I968) leading to raised intraocular pressure. In two of the patients reported in this communication (III, 3 and 5), it was noted that posterior embryotoxon was present, and in one of thesèthe intraocular pressure was raised. We have, however, no record available of gonioscopi examination of the angles.

The presence of ptosis is an unusual feature which has not occurred in pedigrees reported to date. As there is good levator action and a normal Bell's phenomenon, it is proposed, to correct the defect surgically. This patient also has facial asymmetry, which is unif common, though maxillary hypoplasia and mandibular dysostosis have been reported.

Abnormalities other than ocular have not often been noted, though in three of the patients in the present series there was hare lip and cleft palate. This abnormality of closure of the foetal fissures has been reported previously (Zaikova and Bulatovskaya, i $968 \frac{}{\bar{k}}$ and in addition Duggan and Hassard ( I 96 I) recorded aural, dental, and digital anomalies $\overrightarrow{0}$ Mental dullness has been occasionally reported (Duggan and Hassard, I96I) and two of the patients in the present series were mentally subnormal, one to the extent that he needef to be cared for in an institution. Anencephaly in such a pedigree has not been recordeck previously. It is unfortunate that we have no record of the ocular state of this anence phalic infant.

Patient I, I had localized lens opacities in both eyes in the area beneath the colobomata Duke-Elder (1964) stated that this association of abnormalities was sometimes seen 3 Nixseaman (1968) had occasion to perform a lens extraction in a patient with congenita年 iris colobomata, and described the technique for removal of the lens via an inferior cornea? section. In his patient senile cataractous changes were superimposed on the congenita? defect.

\section{Summary}

A family is described in which ten patients in three generations had uveal colobomata with other ocular and systemic abnormalities. These anomalies are discussed with referencer to the literature.

My thanks are due to Mr. P. A. Graham and Mr. W. E. Rees for allowing me to study their patients and to Miss Gail Ferguson for secretarial assistance.

\section{References}

AMmANN, F., KLEIN, D., and JöHR, P. (I964) Ophthalmologica (Basel), 147, I I 8 BATRA, D. v., and PAUl, s. D. (1967) Brit. J. Ophthal., 51, 627

Bernhard, P. ( I 898) Arch. Augenheilk., 37, 5 I

burian, H. M., braley, A. E., and allen, L. (1954) Trans. Amer. ophthal. Soc., 52, 389

coscas, G. (1969) Clin. Ophthal., No. 2, p. 5

Duggan, J. W., and Hassard, D. T. R. (196I) Trans. Canad. ophthal. Soc., p. 2 Io 
DUKE-ELDER, s. (1964) “System of Ophthalmology", vol. 3, p. 2, p. 463, Kimpton, London. ERNYEI, s. (1969) Eye, Ear, Nose, Thr. Mthly, 48, 39

FRANÇOIS, J., NeEtens, A., and CARPENTIER, G. (1964) Bull. Soc. belge Ophtal., no. I 37, p. 294

HAUSCHILD, E. (1969) Acta ophthal. (Kbh.), 47, 926

JERNDAL, T. (1968) Ibid., 46, I 53

кelecom, J. (1967) Rev. Méd. Liège, 22, 52 I

LEWAllen, w. M., JR. (1958) A.M.A. Arch. Ophthal., 59, $83^{1}$

MALIK, s. R. K., SINGH, G., and GUPTA, A. K. (1969) J. All-India ophthal. Soc., 17, I 5

McKusick, v. A. (1966) "Heritable Disorders of Connective Tissue", 3rd ed., p. 5. Mosky. St.

Louis

Mello e oliveira, H. DE (196I) Arch. bras. Oftal., 24, 6

MENDERES, G. (1962) IVth Turk. Oftal. Kong. Bult, 168

MONAHAN, R. H., HILl, C. W. and venters, H. D. (1967) Amer. J. Ophthal., 64, 529

NIXSEAMAN, D. H. (1968) Brit. F. Ophthal., 52, 625

petrovic-Ducic, M. (1959) Med. Arkh. (Sarayevo), 12, i 33

ROY, I. s. (1965) Proc. All-India ophthal. Soc., 22, 98

SRIVASTAVA, s. P. (1961) Brit. F. Ophthal., 45, 382

YANOFf, M., FRAYER, W. c., and scheIE, H. G. (1963) Arch. Ophthal., 70, 372

zaikova, м. v., and BUlatovskaya, B. (1968) Oftal. Zh., 23, No. I, p. 54

ZEITER, H. J. (1963) Amer. J. Ophthal., 55, 910

zolog, N. (1966) Ann. Oculist. (Paris), 199, 885 